\title{
DENTAL MATURITY, ORAL HYGIENE AND HEIGHT OF JUNIOR HIGH SCHOOL STUDENTS IN GOITER ENDEMIC AREA IN KARANGANYAR REGENCY
}

\author{
Risya Cilmiaty ${ }^{1}$, Selfi Handayani², Widia Susanti ${ }^{1}$ \\ 1)Graduate Studies in Medical Science, Graduate Program/ Department of \\ Oral and Dental Hygiene, Faculty of Medicine, Sebelas Maret University \\ ${ }^{2)}$ Graduate Studies in Medical Science, Graduate Program/Department of \\ Anatomy, Faculty of Medicine, Sebelas Maret University
}

\begin{abstract}
BACKGROUND: Geographical condition may affect human behavior and phyisical development. Soil and water in goiter endemic areas generally lack of iodine. This study aimed to determine dental maturity, oral hygiene, and height of junior high school students in goiter endemic area.

SUBJECT AND METHODS: This cross sectional study was conducted in a goiter endemic area in Ngargoyoso, Karanganyar regency, Central Java, with junior high school students were taken by purposive sampling as study sample. The dependent variables included dental maturity, oral hygiene, and height. Dental maturity was assessed by counting the number of tooth eruption. Oral hygiene was assessed by the number of OHI-S. Height was measured by microtoise. Chi Square test was used to test differences.

RESULTS: There were 208 students aged 12 to 15 years, consisting of 96 boys (46.2\%) and 112 girls (53.8\%). Dental maturity of girls were better than dental maturity of boys, and it was statistically significant $(\mathrm{p}=0.006)$. As many as 51 boys (53.1\%) had complete and 45 boys (46.9\%) had incomplete dental maturity. As many as 80 girls $(76.4 \%)$ had complete and 32 girls (28.6\%) had incomplete dental maturity. Oral hygiene between both sexes was comparable, and it was not statistically significant $(\mathrm{p}=$ 0.180 ). As many as 15 boys (15.6\%) had good, 76 boys (79.2\%) had moderate, and 5 boys $(5.2 \%)$ had poor oral hygiene. As many as 18 girls (16.1\%) had good, 80 girls (71.4\%) had moderate, and 14 girls (12.5\%) had poor oral hygiene. Mean height of boys was $151 \mathrm{~cm}$, with maximum height of $173 \mathrm{~cm}$ and minimum height of $126 \mathrm{~cm}$. Mean height of girls was 149 $\mathrm{cm}$, with maximum height of $171 \mathrm{~cm}$ and minimum height of $136 \mathrm{~cm}$. The mean height of junior high school students in goiter endemic area in Ngargoyoso district was still normal compared with non-goiter endemic area.

CONCLUSION: Dental maturity of girls were better than dental maturity of boys. Most of oral hygiene of junior high school students were in the medium category. Oral hygiene between both sexes was comparable. The mean height of junior high school students in goiter endemic area in Ngargoyoso district was still normal.
\end{abstract}

Keywords: dental maturity, oral hygiene, height, goiter endemic areas 